\title{
Effects of Early Childhood Teachers' Mathematics Anxiety on the Development of Children's Mathematical Competencies
}

\author{
Jenßen, L., Hosoya, G., Eilerts, K., Eid, M., \& Blömeke, S.
}

\begin{abstract}
Children develop their mathematical competencies already during their early years. Therefore, effective learning environments provided by early childhood teachers are required. Early childhood teachers' professional competence in mathematics is assumed to consist of different facets such as mathematical content knowledge and affective-motivational dispositions. Mathematics anxiety appears to be a common phenomenon amongst early childhood teachers and it is assumed that children educated by high math anxious teachers develop less mathematical competencies. To test this assumption, $n=48$ early childhood teachers were tested regarding their mathematics anxiety and mathematical content knowledge and $n=362$ corresponding children were tested twice within eight months regarding their mathematical competencies. Results indicate that children gain mathematical competencies over the eight-month period and that early childhood teachers' knowledge and anxiety in mathematics are negatively related. However, no effects of teachers' knowledge or anxiety on children's mathematical development were found. The discussion considers methodological implications and emphasizes limitations with respect to differences between the preschool context and primary or secondary school contexts.
\end{abstract}

Keywords: early childhood teacher, mathematical development, early childhood education, mathematics anxiety, mathematical content knowledge

\section{Introduction}

The importance of early education in mathematics for children's competence development cannot be neglected and is of growing interest in research (Linder and Simpson 2017). Developing children's mathematical competence requires structured and systematic learning environments (Benz et al. 2016). Early Childhood Education and Care (ECEC) institutions intend to provide such mathematical learning environments; however, to succeed in this respect pedagogical professionals need mathematics-related knowledge regarding teaching mathematics, for example knowledge about designing effective learning environments, as well as regarding mathematical content domains (Tsamir et al. 2014; Bents et al. 2016; Dunekacke et al. 2016).

Studies revealed positive effects of ECEC institutions on the cognitive development of children in mathematics (Ulferts and Anders, 2016). However, the role of ECEC teachers' emotions and to what extent they may promote or hinder children's competence development has not yet been examined. Emotions have an impact on learning mathematics in various ways (Schukajlow et al. 2017): Emotions directly and indirectly affect (mathematical) learning (Pekrun 2006), they mediate the transmission of mathematics knowledge to everyday life situations (Jansen et al. 2016), and they influence teachers' instructional strategies (Frenzel et al. 2017). Affective-motivational dispositions are conceptualized as inherent parts of early childhood teachers' professional competence (e.g., Tsamir et al. 2014). However, early childhood teachers' emotions related to mathematics and their effects on children's learning 
of mathematics have yet to be examined. This is the purpose of the present longitudinal study carried out in the Pro-KomMa project. ${ }^{1}$

\section{Children's Mathematical Development in ECEC}

Children start to acquire mathematical competence long before entering primary school (Benz et al. 2016). This mathematical development is assumed to happen constantly and children differ substantially at the end of preschool in their mathematical competence (Gervasoni and Perry 2015). Early mathematical competencies in the content domain "numbers and quantity" strongly predict later achievement in mathematics (Krajewski and Schneider 2009; Nguyen et al. 2016). Although a variety of mathematical content domains can be regarded as relevant for ECEC (Clements and Sarama 2011), theories and research have therefore strongly focused on the domain "numbers and quantity" (Dunekacke et al. 2018).

These competencies are characterized through "logical operations", such as one-to-one assignments, invariance or part-whole relationships (Piaget and Szeminska 1975), a developing concept of numbers, for instance, reading and writing numbers (Clements and Sarama 2011) or, for example, through specific counting principles such as the cardinal principle (Gelman and Gallistel 1978). In particular, the link between numbers and quantities through a developing mathematical set is assumed to be a crucial factor (e.g., Resnick 1989). Consequently, current models, like the model by Krajewski regarding the development of the number concept, highlight the cognitive connection between quantities and numbers for children's mathematical development (Krajewski and Schneider 2009). With respect to this model, children show firstly basic mathematical competencies like seeing differences in size or knowing numerals. In the next stage, children link numerals with quantities (representation of sets) and relate quantities (e.g., part-whole relations) and, finally, they are able to compose and decompose numbers or form differences of specific numbers. The Pro-KomMa assessment of children's development in mathematics follows this model (see section "Instruments" below).

Studies about learning mathematics through ECEC emphasize the importance of interactions between early childhood teacher and child (Doctoroff et al. 2016; Graziano et al. 2007; Trawick-Smith et al. 2015). In particular, early childhood teachers' professional competence is expected to be highly important for children's acquisition of mathematics (Tirosh, Tsamir, Levenson, \& Tabach, 2011).

\section{Early Childhood Teachers' Professional Competence}

Professional competence can be conceptualized as a conglomerate of different dimensions: cognitive dispositions (knowledge), affective-motivational dispositions (e.g. beliefs and emotions), situation-specific skills (e.g. perception, interpretation, decision-making), and observable performance (Blömeke et al. 2015a). Specific models concerning early childhood teachers also claim these different facets. Tsamir et al. (2014) highlight affective-motivational orientations (math-related self-efficacy) besides cognitive dispositions as the core of early childhood teachers' professional competence. Gasteiger and Benz (2018) propose a complex model, which can be considered an application and advancement of the competence conceptualization of Blömeke et al. (2015a). Besides different kinds of knowledge facets, the

\footnotetext{
${ }^{1}$ Pro-KomMa (Professionalization of Early Childhood Teacher Education) is a is a collaborative research project of Humboldt-Universität zu Berlin, Freie Universität Berlin and Alice Salomon University of Applied Sciences within the German research program Modeling and Measuring Competencies in Higher Education - Validation and Methodological Innovations (KoKoHs), funded by the Federal Ministry of Education and Research (BMBF).
} 
authors describe a cluster of attitudes, beliefs, and motivational orientations; a concrete description and opertionalization, however, lacks. Other frameworks highlight performanceorientated competencies of early childhood teachers besides knowledge (e.g. Ginsburg et al. 2008; Clements and Sarama 2011).

The Pro-KomMa framework that underlies the present study can be situated alongside the models by Blömeke et al. (2015a) and Gasteiger and Benz (2018). One of its major assumptions is a significant relation between early childhood teachers' affective-motivational dispositions (e.g. math-related emotions, such as anxiety) and their mathematics-related knowledge. Another major assumption is that these in turn affect the development of children's mathematical competence (Jenßen et al. 2016).

\section{Mathematics Anxiety}

Mathematics anxiety can be described as a negative emotional response to math-related requirements in a variety of situations, such as in daily life or in academic situations (Cooke et al. 2011), which in turn leads to low achievement in mathematics (Ma 1999). Thus, it can be understood as an achievement emotion (Pekrun 2006). Mathematics anxiety is assumed to consist of different facets: The affective facets consist of feelings of fear of mathematics (primary emotional response) and feelings of helplessness, anger, and shame (secondary emotional response) (Buxton 1982; Cherkas 1992). The cognitive facet can be described as beliefs about ones own failure in mathematics and about mental blocks when working on math-related tasks (Hunt et al. 2014).

People who suffer from mathematics anxiety often report of physiological symptoms such as inner tension, transpiration, and higher muscle tonicity (Hembree 1990). In sum, mathematics anxiety seems to be a negative state that one wants to avoid. Consequently, the typical behavioral tendency coinciding with mathematics anxiety is the avoidance of math-related situations (Chang and Beilock 2016). People who report higher levels of mathematics anxiety also tend to avoid math-related tasks (Chipman et al. 1992). Although there is a lack of research directly examining such consequences of math anxiety in ECEC teacher, studies reveal that early childhood teachers show lower self-confidence in creating mathematics learning environments and avoid math-related situations in the daily-preschool context (Bates et al. 2013).

Biological (e.g. genetics), psychological (e.g. introverted personality), social (e.g. negative parenting style), and pedagogical factors (e.g. lack of adequate mathematics education or right-or-wrong conceptions of mathematics at school) determine the development of mathematics anxiety (Ramirez et al. 2018). In accordance with Pekrun's Control-Value theory (Pekrun 2006), it can be assumed, that mathematics anxiety develops in light of two main appraisals: The value appraisal describes the importance of a domain, in this case mathematics, while the control appraisal describes the resources in a domain needed to meet a challenge (mainly cognitive resources, e.g. knowledge to solve mathematical tasks).

According to Benz (2012) and Thiel (2010), the majority of early childhood teachers in Germany reports positive beliefs regarding the importance of mathematics for everyday life and early education. However, positive beliefs about its importance do not necessarily result in positive emotions regarding mathematics. Positive beliefs about the importance of mathematics (value appraisal in terms of Control-Value theory) while believing in one's own low mathematical competence (control appraisal in terms of Control-Value theory) can in contrast result in mathematics anxiety.

It is important to consider that the majority of early childhood teachers are female, and mathematics anxiety is generally more prevalent in females than in males (Stoet et al. 2016). 
Mathematics anxiety is a common phenomenon in early childhood teachers (Bates et al. 2013; Gresham 2008; Gresham and Burleigh 2018). Besides primary school teachers, early childhood teachers describe themselves more often as anxious about mathematics than other pedagogical professionals do (Ginet et al. 2018). Younger pre-service early childhood teachers especially report more often to be anxious about mathematics (Thiel and Jenßen 2018). However, mathematics anxiety seems to not differ between pre-service and in-service early childhood teachers during their career entry (Gresham 2018). In contrary, some studies reveal that in-service early childhood teachers report even higher levels of mathematics anxiety (Aslan 2013). With respect to potential consequences, pre-service early childhood teachers with higher levels of mathematics anxiety show lower content knowledge in all mathematical domains (Jenßen et al. 2015a; Thiel and Jenßen 2018).

\section{Early Childhood Teachers' Mathematics Content Knowledge}

According to Shulman (1986), the cognitive disposition of teachers' professional competence can be differentiated into mathematics content knowledge (MCK), mathematics pedagogical content knowledge (MPCK), and general pedagogical knowledge (GPK). Usually, research on ECEC in the field of mathematics focuses on MPCK. However, an increasing number of studies revealed that MCK is important for perceiving situations from a mathematical point of view, for planning math-related activities (Dunekacke et al. 2015), and for performing adequately in math-related situations (Ginsburg and Ertle 2008; Klibanoff et al. 2006; see also Kaiser and König; and Kuhn et al. in this volume).

In theories and research concerning early education in mathematics, there is a long-standing debate about the nature of MCK needed for fostering children's mathematical competence (Ginsburg and Ertle 2008; Gasteiger and Benz 2018). Descriptions of MCK reach from rather school-orientated definitions (e.g. Tsamir et al. 2014) to conceptualizations of early childhood teachers' implicit MCK (e.g. Gasteiger and Benz 2018). However, all frameworks emphasize the importance of MCK for children's mathematical development.

Bäckman and Attorps (2012) postulate the awareness of content in mathematics. Early childhood teachers like other pedagogical professionals in mathematics have to know mathematics in depth and breadth. Depth of MCK describes the cumulative nature of mathematics, while breadth of MCK describes knowledge about the different mathematical domains. From the perspective of breadth, MCK can be described along the four mathematical domains "numbers, sets, and operations", "shape, space, and change", "quantity, measurement, and relations", and "data, combinatorics, and chance". This conceptualization that also underlies the Pro-KomMa project seems to be internationally valid, when comparing curricula from Germany and the U.S., for example (Jenßen et al. 2013).

However, regarding depth MCK seems to have a low value during early childhood teachers' training in Germany (Blömeke et al. 2017). As mathematics anxiety and MCK interact, reciprocal effects can be assumed (Carey et al. 2016): lower MCK may result in higher anxiety towards mathematics (and vice versa). Due to the hypothesized interaction of MCK and math anxiety, it is necessary to control for their MCK to analyze effects of early childhood teachers' mathematics anxiety.

\section{Effects of Early Childhood Teachers' Math Anxiety and MCK on children's development}

Research on mathematics anxiety highlights the transmission of adults' (e.g. parents or teachers) math anxiety to children (Herts et al. 2019). Consequences of teachers' mathematics 
anxiety for students are broadly discussed. High levels of mathematics anxiety are assumed to lead to high levels of mathematics anxiety and lower levels of mathematics knowledge in their students (Bekdemir 2010; Chang and Beilock 2016; O'Leary et al. 2017). In particular, transmissive models concerning emotions of teachers via their corresponding instructional behavior to their students, such as less process-orientated teaching strategies, might be an explanatory factor as well as children's perception of teachers' negative beliefs regarding the nature of mathematics (Hadley and Dorward 2011; Ramirez et al. 2018; Herts et al. 2019; Frenzel et al. 2017). The transmissive power of math-specific beliefs or gender stereotypes in adult-child-interactions may be also explanatory factors (Herts et al. 2019).

So far, the assumed link between teachers' high level of mathematics anxiety and students' low level of mathematics achievement could only be validated empirically for primary and secondary school teachers (Beilock et al. 2010; Hadley and Dorward 2011; Ramirez et al. 2018). Within the context of ECEC, many factors regarding early childhood teachers due to higher math anxiety could be theoretically assumed as explanations for children's potentially lower achievement in mathematics: Negation of the importance of mathematics in ECEC, underestimation of mathematics activities in preschool, resulting in lower mathematics content knowledge, avoidance of math-related situations and/or transmission of negative thoughts and feelings in interactions. The opportunity for avoidance of math-related situations might be particularly prevalent within the informal learning context of ECEC. With respect to early childhood teachers, with the exception of one study that is characterized by methodological problems (Aslan et al. 2013), no empirical validation of a transmission assumption regarding math anxiety exists. Our longitudinal study is the first of its kind.

While effects of teachers' MCK on children's achievement can be found for primary school (e.g. Hill et al. 2005), empirical studies for early childhood teachers are lacking, with the exception of a few qualitative studies (Tirosh et al. 2011). Although limited generalization these studies indicate that it might be an advantage for children's mathematical development if their ECEC teachers dispose of rich MCK. Although MCK mainly serves as a control variable in our study, it will be possible to examine this relationship as a side effect.

\section{Research Questions and Hypothesis}

The present longitudinal study investigates whether early childhood teachers' mathematics anxiety shows effects on children's mathematical development. Teachers' MCK is included in the model to control for cognitive dispositions of professional competence. In line with the transmission theory, we hypothesize that ECEC teachers' mathematics anxiety has a negative effect on children's mathematical development $(\mathrm{H} 1)$. Derived from theoretical assumptions and empirical studies, we hypothesize in contrast that their MCK has a positive effect $(\mathrm{H} 2)$. As indicated by the state of research, we assume a negative relation of medium size between mathematics anxiety and MCK $(\mathrm{H} 3)$. As research on direct effects of early childhood teachers' emotion on children's mathematical development is scarce, we refrain from hypothesizing the size of potential effects.

\section{Instruments}

To assess early childhood teachers' MCK, the KomMa-MCK-Test (Blömeke et al. 2015b) was used. The test consists of 24 items covering four mathematical domains of early education (numbers, sets, and operations; shape, space, and change; quantity, measurement, and relations; data, combinatorics, and chance). Each domain consists of six items in multiplechoice and open-response format. The test has been validated in multiple studies regarding content (Jenßen et al. 2015b), structure (Blömeke et al. 2015b), and relation to other 
variables, such as learning opportunities during early educators' training (Blömeke et al. 2017), beliefs (Dunekacke et al. 2016), situation-specific perception (Dunekacke et al. 2015), and general cognitive abilities (Blömeke and Jenßen 2017). Figure 1 shows an example of a multiple-choice item concerning the domain "data, combinatorics, and chance".

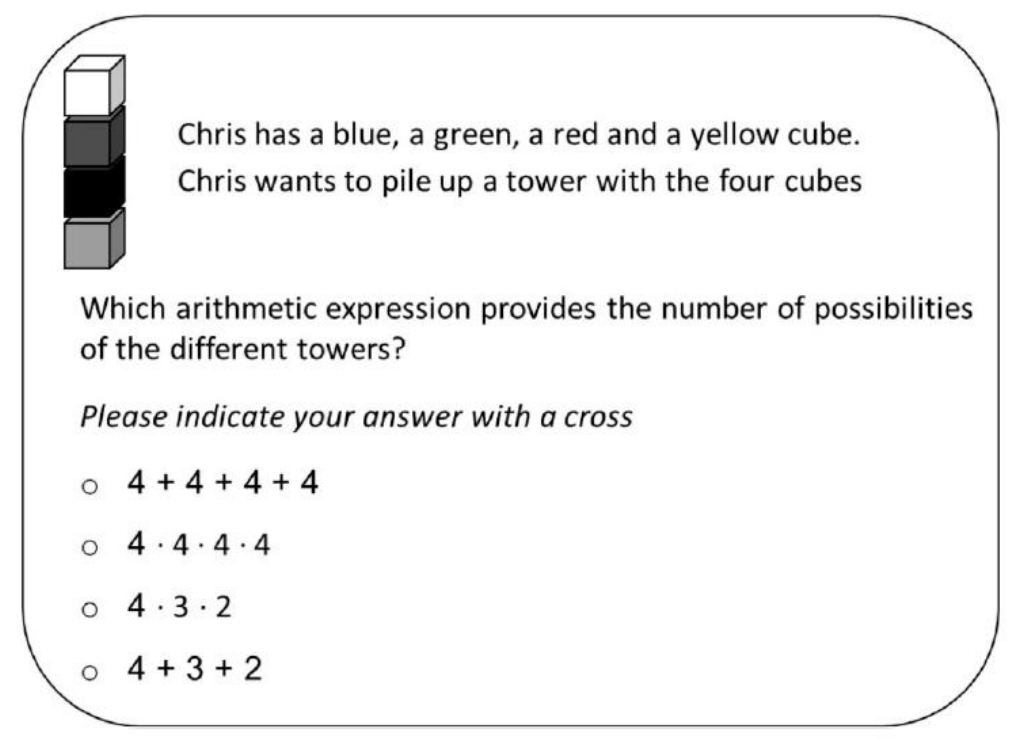

Figure 1. Example item from the KomMa-MCK-Test (translated)

Mathematics anxiety was assessed using the Mathematics Anxiety Scale - Revised (MAS-R) (Bai et al. 2009). The questionnaire contains 14 items of which six are positive statements (e.g. "I find math interesting") and eight are negative statements (e.g. "Mathematics makes me feel nervous."). Answers had to be rated on a five-point Likert scale ranging from "totally agree" to "totally disagree." Positive statements have to be inverted so high scores indicate higher anxiety towards mathematics. Bai et al. state that negative statements of the assessment reflect the affective facet of mathematics anxiety and the (later inverted) positive statement reflect the cognitive facet. In the past, MAS-R was used to assess pre-service early childhood teachers' mathematics anxiety in different research contexts including Germany (Jenßen et al., 2015a; Thiel and Jenßen 2018) and can be consider valid concerning relations to other variables and factorial structure (Bai et al. 2009).

A standardized assessment well-established in Germany was used to test children's mathematical achievement (Test mathematischer Basiskompetenzen im Kindergarten, MBK 0 ; Krajewski 2018). The test is based on Krajewski's model of the development of children's quantity-number competencies (Krajewski and Schneider 2009) and considers three major areas: number meaning, sets of numbers, and number relations. Tasks contain typical procedures of children's mathematical activities such as counting forward, naming numerals, ordering numbers, and comparing quantities. The test can be predominantly applied for below average and average areas on the achievement continuum.

\section{Participants and Procedure}

$N=362$ children were tested twice within approximately 8 months in their regular preschool context. The children's mean age at the first time-point of assessment on the MBK 0 was $M=1633$ days, respectively 4.5 years, ( $S D=311$ days) and $56 \%$ of the participating children were girls. The MBK 0 was administered by two trained university students. About 8 children were grouped with one early childhood teacher $(M=7.5)$, whereby only one early childhood teacher was related to one preschool, respectively to one group of children. 
About 1.5 months before the second test administration, $n=48$ early childhood teachers' MCK and mathematics anxiety were assessed via an online-based assessment. The teachers' mean age was $M=33$ years ( $S D=9.3)$. One item of the KomMa-MCK-Test concerning "shape, space, and change" had to be excluded for online assessment because of technical difficulty (the open-response item required the drawing of a cuboid, which was not technically possible). The majority of the early childhood teachers were female $(91.7 \%)$ and all teachers were career entrants with five years' experience at a maximum. Teachers received monetary incentives for their participation.

\section{Data Analysis}

A two-level change model for two measurement occasions was specified for data analysis (Figure 2). In Figure 2, $I_{W}$ (intercepts within) represents the children's scores on the MBK 0 on the first measurement occasion and $S_{W}$ (slopes within) represents the children's change on the MBK 0 from time-point 1 to time-point 2. As children are nested within teachers, $I_{B}$ (intercepts between) represents average scores of the children within a group at the first measurement occasion and $S_{B}$ (slopes between) represents the group-specific change of the children's performance on the teacher level.

The group-specific change of the children's performance is regressed on math anxiety as well as on MCK which were assessed on the teacher level. Both variables were standardized on the teacher level in the analysis to allow for a comparison of the effects on the group-specific change and to provide a meaningful interpretation of the intercepts on the teacher level. In addition, the covariance between MCK and math anxiety were modelled.

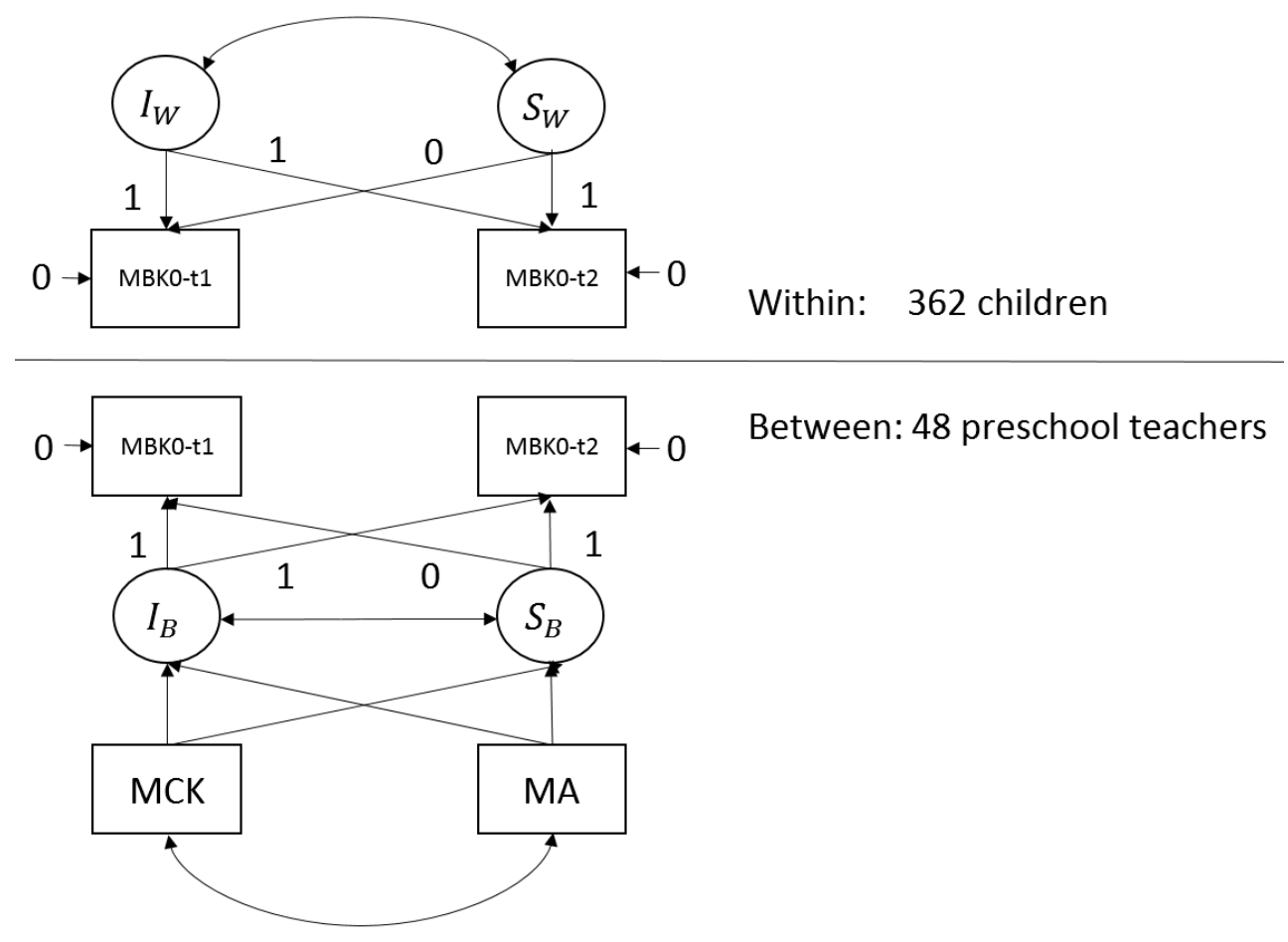

Figure 2. Two-level change model for two measurement occasions. MBK0-t1: MBK 0 scores on the first measurement occasion. MBKO-t2: MBK 0 scores on the second measurement occasion. MCK: Teachers' mathematical content knowledge. MA: Teacher's math anxiety.

The data were analyzed with the software MPlus (Muthén and Muthén 1998-2017), version 8.3. As the data contained a large amount of missing values, only 126 cases contained no missings (Table 1), full information maximum likelihood estimation (FIML) was used. In 
addition, a sensitivity analysis was conducted using multiple imputation using the unrestricted $\mathrm{H} 1$ model to control if the results were stable across different analysis conditions. 100 Imputation datasets and robust maximum likelihood estimation (MLR) were used.

Table 1. Frequencies $(n)$ of missingness patterns in the data set $(N=362)$.

\begin{tabular}{|c|c|c|c|c|c|c|c|c|c|c|}
\hline & $\begin{array}{c}\text { Pattern } \\
1 \\
(n=126)\end{array}$ & $\begin{array}{c}\text { Pattern } \\
2 \\
(n=82)\end{array}$ & $\begin{array}{c}\text { Pattern } \\
3 \\
(n=56)\end{array}$ & $\begin{array}{c}\text { Pattern } \\
4 \\
(n=46)\end{array}$ & $\begin{array}{c}\text { Pattern } \\
5 \\
(n=19)\end{array}$ & $\begin{array}{c}\text { Pattern } \\
6 \\
(n=10)\end{array}$ & $\begin{array}{c}\text { Pattern } \\
7 \\
(n=8)\end{array}$ & $\begin{array}{c}\text { Pattern } \\
8 \\
(n=6)\end{array}$ & $\begin{array}{c}\text { Pattern } \\
9 \\
(n=7)\end{array}$ & $\begin{array}{c}\text { Pattern } \\
10 \\
(n=2)\end{array}$ \\
\hline MAS-R & $X$ & $x$ & & & $x$ & & $x$ & & & \\
\hline MCK & $x$ & $x$ & & & $x$ & & $x$ & $x$ & $x$ & $X$ \\
\hline $\begin{array}{l}\text { MBK } 0 \\
\mathrm{t} 1\end{array}$ & $x$ & $x$ & $x$ & $x$ & & & & $x$ & $x$ & \\
\hline $\begin{array}{l}\text { MBK } 0 \\
\mathrm{t} 2\end{array}$ & $x$ & & & $x$ & $x$ & $x$ & & & $X$ & $X$ \\
\hline
\end{tabular}

Note. X: not missing. MAS-R: Math Anxiety Scale Revised; MCK: Mathematical Content Knowledge, MBK 0 t1: Children's competence on first measurement occasion; MBK 0 t2: Children's competence on second measurement occasion.

\section{Results}

For $n=30$ early childhood teachers MCK scores were available. Scores of the KomMa-MCK-Test can range from 0 to 23 points. On average, teachers reached 12.9 points $(S D=6.04, \min =1$, $\max =22)$. The MAS-R scores can range from 14 to 70 points. Mathematics anxiety scores were available for $n=28$ teachers $(M=40.4, S D=11.00, \min =16, \max =61)$.

Table 2 shows the results of the analysis. With FIML-estimation, the estimated average score of the children on the MBK 0 at the first measurement occasion is $\beta=14.4 \quad(p<.001)$. On average, the children's groups gained 8 points on the MBK 0 from measurement occasion 1 to measurement occasion $2(p<.001)$. The minimum score achievable on the MBK 0 is 0 points, the maximum score is 44 points.

When using FIML estimation, the estimated effect of math anxiety on the children's groups' gain-scores is negative and statistically significant $(\beta=-1.4 ; p=.04)$, as hypothesized $(\mathrm{H} 1)$ : with a self-reported increase in ECEC teachers' math anxiety of one standard deviation (11 points on the math anxiety scale), their children group's gains were reduced by expected 1.4 points compared to a group with an ECEC teacher of similar MCK.

In contrast to our hypothesis ( $\mathrm{H} 2)$, there was no significant effect of MCK on the children's groups' development ( $\beta=-1.128 ; p=.198)$ when controlling for math anxiety. Together, math anxiety and MCK explain $28.6 \%(p=.181)$ of the variance in the children's groups' gain scores. However, the variance explained is statistically not significant.

In line with our hypothesis (H3), the covariance of math anxiety with MCK on the between level is negative $(\beta=-0.51 ; p<.028)$ and statistically significant, indicating that teachers with a high level of math anxiety are more likely to have lower MCK. The respective estimated correlation between math anxiety and $\mathrm{MCK}$ is $\rho=-.50$ and thus quite strong.

The estimates using multiple imputation are relatively similar to those obtained by FIML estimation. However, the estimated effect of math anxiety on the children's performance is statistically not significant $(\beta=-1.1 ; p=.265)(\mathrm{H} 1)$. The estimated effects for the expected average gain of the children on the $\operatorname{MBK} 0(\beta=7.7 ; p<.001)$ and the negative covariance between math anxiety and $\operatorname{MCK}(\beta=-0.49 ; p=.048)$ with a respective correlation of $\rho=-.47$ remain robust across analysis methods. One reason for the divergence between the FIML- and multiple imputation analyses could lie on a large amount of missing data. Multiple imputation considers the uncertainty induced by the missing data and, thus, the method may result in 
slightly different estimates as well as, in some cases, slightly larger standard errors as compared to FIML estimation.

Table 2. Estimated unstandardized model coefficients for full information maximum likelihood (FIML) and Multiple Imputation (MI)

\begin{tabular}{|c|c|c|c|c|c|}
\hline & $\begin{array}{l}\text { FIML-Estimate } \\
(S E)\end{array}$ & $\begin{array}{l}\text { FIML } p- \\
\text { value }\end{array}$ & MI-Estimate $(S E)$ & MI p-Value & $\begin{array}{l}\text { Rate of } \\
\text { Missings }\end{array}$ \\
\hline \multicolumn{6}{|l|}{ Within Level } \\
\hline SW with IW & $\begin{array}{l}-18.099 \\
(4.803)\end{array}$ & $<.001$ & $-19.168(5.805)$ & $<.01$ & .556 \\
\hline \multicolumn{6}{|l|}{ Variances } \\
\hline IW & $\begin{array}{r}79.174 \\
(8.991)\end{array}$ & $<.001$ & $78.413(8.364)$ & $<.001$ & .077 \\
\hline SW & $\begin{array}{c}47.234 \\
(5.430)\end{array}$ & $<.001$ & $49.642(6.265)$ & $<.001$ & .575 \\
\hline \multicolumn{6}{|l|}{ Between Level } \\
\hline IB on Math Anxiety & $\begin{array}{l}-0.118 \\
(1.766)\end{array}$ & .947 & $0.625(2.068)$ & .762 & .566 \\
\hline IB on MCK & $\begin{array}{c}1.743 \\
(2.261)\end{array}$ & .441 & $2.037(2.065)$ & .324 & .477 \\
\hline SB on Math Anxiety & $\begin{array}{l}-1.389 \\
(0.687)\end{array}$ & .043 & $-1.083(0.972)$ & .265 & .486 \\
\hline SB on MCK & $\begin{array}{l}-1.128 \\
(0.876)\end{array}$ & .198 & $-0.793(1.069)$ & .458 & .536 \\
\hline SB with IB & $\begin{array}{l}-4.209 \\
(6.440)\end{array}$ & .513 & $-5.050(7.532)$ & .503 & .405 \\
\hline $\begin{array}{l}\text { Math Anxiety with } \\
\text { MCK }\end{array}$ & $\begin{array}{l}-0.506 \\
(0.230)\end{array}$ & .028 & $-0.490(0.248)$ & .048 & .547 \\
\hline \multicolumn{6}{|l|}{ Means } \\
\hline Math Anxiety & $\begin{array}{c}0.095 \\
(0.186)\end{array}$ & .612 & $0.070(0.193)$ & .716 & .436 \\
\hline MCK & $\begin{array}{l}-0.003 \\
(0.196)\end{array}$ & .987 & $-0.005(0.184)$ & .977 & .352 \\
\hline \multicolumn{6}{|l|}{ Intercepts } \\
\hline IB & 14.425 (1.372) & $<.001$ & $14.521(1.390)$ & $<0.001$ & .063 \\
\hline SB & $7.951(0.626)$ & $<.001$ & $7.715(0.804)$ & $<0.001$ & .419 \\
\hline \multicolumn{6}{|l|}{ Variances } \\
\hline Math Anxiety & $0.995(0.261)$ & $<.001$ & $1.014(0.320)$ & $<0.01$ & .605 \\
\hline MCK & $1.035(0.186)$ & $<.001$ & $1.053(0.251)$ & $<0.001$ & .480 \\
\hline \multicolumn{6}{|l|}{ Residual Variances } \\
\hline IB & $\begin{array}{l}79.998 \\
(16.207)\end{array}$ & $<.001$ & 74.720 (15.618) & $<.001$ & .161 \\
\hline SB & $4.130(3.501)$ & .238 & $10.763(6.246)$ & 0.085 & .532 \\
\hline
\end{tabular}

Note. IW: Intercepts within; SW: Slopes within; IB: Intercepts between; SB: Slopes between. MCK:

Mathematical Content Knowledge; Effects of interest are printed in bold font. MCK and math anxiety were standardized on the between level to allow for a comparison of the effects.

\section{Discussion and Conclusions}

Our study contributes to other findings, that children gain mathematical competencies within the ECEC institutions in Germany (Ulferts and Anders 2016). As hypothesized based on results in other studies, early childhood teachers' math anxiety and MCK are negatively associated. However, they seem to be stronger related compared to studies with pre-service early childhood teachers (e.g. Jenßen et al. 2015a; Thiel and Jenßen 2018). These results are robust across analysis methods. 
In this study, no conclusive links between early childhood teachers' characteristics and the development of the children could be established though. Albeit the effect of math anxiety on the children's development is statistically significant using FIML estimation, multiple imputation paints a slightly different picture. The fact that the amount of variance in the group specific gain scores explained by the teacher characteristics is not significant using FIML estimation also stresses the conclusion that no decisive link between teacher characteristics and the children's development could be established. Thus, our study replicates findings by Aslan et al. (2013). However, also this study was characterized by methodological problems such as XXXXX so that further studies are needed to conclusively test a possible link between teacher characteristics and children's development.

In contrast to our hypothesis, early childhood teachers' MCK had no effect on children's mathematical development in the present study. The state of research was already inconclusive in this respect. One explanation could be our conceptualization of early childhood teachers' MCK, which could be described as more orientated towards the transition from ECEC towards primary school and thus towards slightly older children (Blömeke et al. 2015b). Hedges and Cullen (2006) emphasize the importance of early childhood teachers' MCK for children's mathematical development. From a conceptual point of view, they state that early childhood teachers' MCK should be related to children's mathematical knowledge that is needed for mathematical development and for later school achievement. Thus, our conceptualization should reveal an effect in the present study as well but from an empirical point of view, it is still unknown which kind of MCK early childhood teachers need to foster children's mathematical competence. It could be one of the most important desiderata in ECEC research in mathematics, to clarify whether more "child-centered" MCK or more "school-orientated" MCK is needed.

Another explanation could be that we treated the link between MCK and children's development as a "black box". Data is needed about other facets of ECEC teachers' professional competence and their actual behavior in the classroom as well as about other contextual characteristics of children's learning environment including their opportunities to learn mathematics at home. Especially gender-related stereotype beliefs seem to play an important role in the transmission of math anxiety (Herts et al. 2019), but empirical research is still lacking. In this case, it would be possible to specify more complex models that take a broader range of predictors and potentially mediating factors into account. This would require a large range of measures though while it is questionable whether early childhood teachers would take a test battery that lasts for several hours besides their job duties.

There are also some limitations of our study. The representativeness of the teacher sample regarding job experience, gender, and regional specifics during teachers' training in Germany is limited as the participating early childhood teachers were at the beginning of their careers (although some of the early childhood teachers seem to have completed a former different training), mainly female, and were working in Berlin and Brandenburg. Future research should consider these points. In particular, gender seems to be a highly important feature in math (Beilock et al. 2010), especially in the context of ECEC, because the majority of early childhood teachers in Germany are female. It could be also important, that the current study was done in Germany, which shows a more social-educational approach in ECEC as compared to other countries such as the U.S. Moreover, in the current application only one early childhood teacher per group was tested. Usually, there are at least two early childhood teachers responsible for a group of children. From this structural point of view, preschool differs from primary school. Thus, our assumption of the impact of one early childhood teacher's math anxiety on children's mathematical development derived from theories based on primary or 
secondary school structures may be more or less applicable. Additionally, it has to be assumed that learning groups in preschool are more heterogeneous than in primary or secondary school. Acquisition of cognitive competencies or transmission of teachers' beliefs and/or emotions may be less powerful in these heterogeneous groups.

To conclude, although it remains unclear whether math anxiety shows direct effects on children's learning in the ECEC context in Germany, math anxiety seems to be a relevant dispositional facet of early childhood teachers. In itself this is an unfavorable characteristic. Consequently, the reduction of early childhood teachers' mathematics anxiety seems to be a goal for training and practice. A promising intervention for early childhood teachers' mathematics anxiety may be the reduction of the avoidance of math-related situations. Firstly, early childhood teachers have to be aware of their own level of mathematics anxiety. According to Polya (1977), it is mandatory to experience mathematics as a domain full of positive aspects, so that the teacher gains positive feelings and thoughts concerning mathematics. Secondly, mathematics has to be valued as an important subject by early childhood teachers within the ECEC context. Thirdly, with respect to Control-Value Theory (Pekrun 2006), it is necessary for early childhood teachers to think positively about their own resources as a way of coping with challenging mathematical tasks in ECEC situations. Early childhood teachers need to develop their own MCK during training (Blömeke et al. 2017), so that they feel competent in mathematics (Thiel and Jenßen 2018).

\section{References}

Aslan, D. (2013). A comparison of pre- and in-service preschool teachers' mathematical anxiety and beliefs about mathematics for young children. Academic Research International, 4(2), 225-230. Retrieved from http://www.savap.org.pk/journals/ARInt./Vol.4(2)/2013(4.2-22).pdf

Aslan, Durmuş, Oğul, i. G., \& Taş, I. (2013). The Impacts of Preschool Teachers' Mathematics Anxiety and Beliefs on Children's Mathematics Achievement. International Journal of Humanities and Social Science Invention, 2(7), 45-49.

Bai, H., Wang, L., Pan, W., \& Frey, M. (2009). Measuring mathematics anxiety: Psychometric analysis of a bidimensional affective scale. Journal of Instructional Psychology, 36(3), 189-193. Retrieved from http://psycnet.apa.org/psycinfo/2009-20155-001

Bäckman, K., \& Attorps, I. (2012). Teaching mathematics in the pre-school context. US-China Education Review, 1-16.

Bates, A. B., Latham, N. I., \& Kim, J. (2013). Do I Have to Teach Math? Early Childhood PreService Teachers' Fears of Teaching Mathematics. IUMPST: The Journal, 5(August).

Beilock, S. L., Gunderson, E. A., Ramirez, G., \& Levine, S. C. (2010). Female teachers' math anxiety affects girls' math achievement. Proceedings of the National Academy of Sciences, 107(5), 1860-1863. https://doi.org/10.1073/pnas.0910967107

Bekdemir, M. (2010). The pre-service teachers' mathematics anxiety related to depth of negative experiences in mathematics classroom while they were students. Educational Studies in Mathematics, 75(3), 311-328. https://doi.org/10.1007/s10649-010-9260-7

Benz, C. (2012). "Maths is not dangerous" - Attitudes of people working in German kindergarten about mathematics in kindergarten". European Early Childhood Education Journal, 20(2), 249-261. doi:10.1080/1350293X.2012.681131

Benz, C., Steinweg, A.S., Gasteiger, H., Schöner, P., Vollmuth, H., \& Zöllner, J. (2018). Mathematics education in the early years. Cham, Switzerland: Springer International.

Blömeke, S., Gustafsson, J.-E., \& Shavelson, R. J. (2015a). Competence viewed as a continuum. Zeitschrift für Psychologie, 223(1), 3-13. https://doi.org/10.1027/2151-2604/a000194 
Blömeke, S., \& Jenßen, L. (2017). A question of validity: Clarifying the hierarchical nature of teacher cognition. In M. Rosén, K. Y. Hansen, \& U. Wolff (Eds.), Cognitive abilities and educational outcomes. A festschrift in honour of Jan-Eric Gustafsson (pp. 89-110). Cham, Switzerland: Springer International Publishing.

Blömeke, S., Jenßen, L., Dunekacke, S., Suhl, U., Grassmann, M., \& Wedekind, H. (2015b). Leistungstests zur Messung der professionellen Kompetenz frühpädagogischer Fachkräfte. Zeitschrift Für Pädagogische Psychologie, 29(3-4), 177-191. https://doi.org/10.1024/1010-0652/a000159

Blömeke, S., Jenßen, L., Grassmann, M., Dunekacke, S., \& Wedekind, H. (2017). Process Mediates Structure: The Relation Between Preschool Teacher's Education and Preschool Teachers' Knowledge. Journal of Educational Psychology, 109(3), 338-354. https://doi.org/10.1037/edu0000147

Carey, E., Hill, F., Devine, A., \& Szücs, D. (2016). The chicken or the egg? The direction of the relationship between mathematics anxiety and mathematics performance. Frontiers in Psychology, 6, 1-6. https://doi.org/10.3389/fpsyg.2015.01987

Chang, H., \& Beilock, S. L. (2016). The math anxiety-math performance link and its relation to individual and environmental factors: A review of current behavioral and psychophysiological research. Current Opinion in Behavioral Sciences, 10, 33-38. https://doi.org/10.1016/j.cobeha.2016.04.011

Chipman, S. F., Krantz, D. H., \& Silver, R. (1992). Mathematics Anxiety and Science Careers Among Able College-Women. Psychological Science, 3(5), 292-295. https://doi.org/10.1111/j.1467-9280.1992.tb00675.x

Clements, D. H., \& Sarama, J. (2011). Early childhood mathematics intervention. Science, 333, 968-970. doi: 10.1126/science.1204537

Cooke, A., Cavanagh, R., Hurst, C. \& Sparrow, L. (2011). Situational effects of mathematics anxiety in pre-service teacher education. Paper presented at the 2011 AARE international Research Conference, Hobart, Australia, 27 November-1 December, 2011. Retrieved from http://www.aare.edu.au/data/publications/2011/aarefinal00501.pdf

Doctoroff, G. L., Fisher, P. H., Burrows, B. M., \& Edman, M. T. (2016). Preschool children's interest, social-emotional skills, and emergent mathematics skills. Psychology in the Schools, 53(4), 390-403. https://doi.org/10.1002/pits

Dunekacke, S., Grüßing, M., \& Heinze, A. (2018). Is considering numerical competence sufficient? The structure of 6-year-old preschool children's mathematical competence. In C. Benz, A.S. Steinweg, H. Gasteiger, P. Schöner, H. Vollmuth, \& J. Zöllner (Eds.), Mathematics education in the early years (pp. 145-157). Cham, Switzerland: Springer International.

Dunekacke, S., Jenßen, L., \& Blömeke, S. (2015). Effects of Mathematics Content Knowledge on Pre-school Teachers' Performance: a Video-Based Assessment of Perception and Planning Abilities in Informal Learning Situations. International Journal of Science and Mathematics Education, 13(2), 267-286. https://doi.org/10.1007/s10763-014-9596-z

Dunekacke, S., Jenßen, L., Eilerts, K., \& Blömeke, S. (2016). Epistemological beliefs of prospective preschool teachers and their relation to knowledge, perception, and planning abilities in the field of mathematics: a process model. ZDM - Mathematics Education, 48(1-2), 125-137. https://doi.org/10.1007/s11858-015-0711-6

Frenzel, A. C., Becker-kurz, B., Pekrun, R., Goetz, T., Lüdtke, O., Frenzel, A. C., ... Lüdtke, O. (2017). Reciprocal effects model of teacher and student emotion transmission in the classroom revisited: A reciprocal effects model of teacher and student enjoyment. Journal of Educational Psychology, 1-12. 
Gasteiger, H., \& Benz, C. (2018). Mathematics education competence of professionals in early childhood education: A theory-based competence model. In C. Benz, A.S. Steinweg, H. Gasteiger, P. Schöner, H. Vollmuth, \& J. Zöllner (Eds.), Mathematics education in the early years (pp. 69-92). Cham, Switzerland: Springer International.

Gelman, R. \& Gallistel, C.R. (1978). The child's understanding of number. Cambridge, MA: Harvard University Press.

Gervasoni, A., \& Perry, B. (2015). Children's mathematical knowledge prior to starting school and implications for transition. In B. Perry, A. MacDonald, \& A. Gervasoni (Eds.), Mathematics and transition to school (pp. 47-64). Wiesbaden, Germany: Springer.

Ginet, L., Itzkowich, R., \& Maloney, E. (2018). Math anxiety and math performance: How do they relate? In J.S. McCray, J.-Q. Chen, \& J.E. Sorkin (Eds.), Growing mathematical minds. Conversations between developmental psychologists and early childhood teachers (pp. 173-200). New York: Routledge.

Ginsburg, H. P., Lee, J. S., \& Boyd, J. S. (2008). Mathematics education for young children: What it is and how to promote it. Social Policy Report - Giving Child and Youth Development Knowledge Away, 22(1), 1-24.

Ginsburg, H. P., \& Ertle, B. (2008). Knowing the mathematics in early childhood mathematics. In O. N. Saracho \& B. Spodek (Eds.), Contemporary perspectives on mathematics in early childhood education (pp. 45-66). Charlotte, NC: Information AGE.

Graziano, P. A., Reavis, R. D., Keane, S. P., \& Calkins, S. D. (2007). The role of emotion regulation in children's early academic success. Journal of School Psychology, 45, 3-19. https://doi.org/10.1016/j.jsp.2006.09.002

Gresham, G. (2008). Mathematics anxiety and mathematics teacher efficacy in elementary pre-service teachers. Teaching Education, 19(3), 171-184. https://doi.org/10.1080/10476210802250133

Gresham, G. (2018). Preservice to Inservice: Does Mathematics Anxiety Change With Teaching Experience? Journal of Teacher Education, 69(1), 90-107. https://doi.org/10.1177/0022487117702580

Gresham, G., \& Burleigh, C. (2018). Exploring early childhood preservice teachers' mathematics anxiety and mathematics efficacy beliefs. Teaching Education, 1-25. https://doi.org/10.1080/10476210.2018.1466875

Hadley, K. M., \& Dorward, J. (2011). Investigating the Relationship between Elementary Teacher Mathematics Anxiety, Mathematics Instructional Practices, and Student Mathematics Achievement. Journal of Curriculum and Instruction, 5(2), 27-44. https://doi.org/10.3776/joci.2011.v5n2p27-44

Hedges, H., \& Cullen, J. (2005). Meaningful teaching and learning: Children's and teachers' content knowledge. ACE Paper: Approaches to Domain Knowledge in Early Childhood Pedagogy, 16, 11-24. Retrieved from https://researchspace.auckland.ac.nz/handle/2292/25146

Hembree, R. (1990). The Nature, Effects, and Relief of Mathematics Anxiety. Journal for Research in Mathematics Education, 21(1), 33-46.

Herts, J.B., Beilock, S.L., \& Levine, S.C. (2019). The role of parents' and teachers' math anxiety in children's math learning and attitudes. In I.C. Mammarella, S. Caviola, \& A. Dowker (Eds.), Mathematics anxiety: What is known and what is still to be understood (pp.190210). London \& New York: Routledge.

Hill, H. C., Rowan, B., \& Ball, D. L. (2005). Effects of Teachers' Mathematical Knowledge for Teaching on Student Achievement. American Educational Research Journal, 42(2), 371406. https://doi.org/10.3102/00028312042002371 
Hunt, T. E., Clark-carter, D., Sheffield, D., \& Hunt, T. E. (2014). Math Anxiety, Intrusive Thoughts and Performance. Journal of Education, Psychology and Social Sciences, 2(2), 69-75.

Jansen, B. R. J., Schmitz, E. A., \& van der Maas, H. L. J. (2016). Affective and motivational factors mediate the relation between math skills and use of math in everyday life. Frontiers in Psychology, 7(APR), 1-11. https://doi.org/10.3389/fpsyg.2016.00513

Jenßen, L., Dunekacke, S., Baack, W., Tengler, M., Wedekind, H., Grassmann, M., \& Blömeke, S. (2013). Validating an assessment of pre-school teachers' mathematical knowledge. Paper presented at the meeting of the International Group for the Psychology of Mathematics Education, Kiel, Germany.

Jenßen, L., Dunekacke, S., Eid, M., \& Blömeke, S. (2015a). The relationship of mathematical competence and mathematics anxiety: An application of latent state-trait theory. Zeitschrift Fur Psychologie / Journal of Psychology, 223(1), 31-38. https://doi.org/10.1027/2151-2604/a000197

Jenßen, L., Dunekacke, S., \& Blömeke, S. (2015b). Qualitätssicherung in der Kompetenzforschung. Kompetenzen von Studierenden. 61. Beiheft Der Zeitschrift Für Pädagogik, 2015, 11-31.

Jenßen, L., Jegodtka, A., Eilerts, K., Eid, M., Koinzer, T., Schmude, C., Rasche, J., Szczesny, M., \& Blömeke, S. (2016). Pro-KomMa - Professionalization of Early Childhood Teacher Education: Convergent, Discriminant, and Prognostic Validation of the KomMa Models and Tests. In H.A. Pant, O. Zlatkin-Troitschanskaia, C. Lautenbach, M. Toepper, \& D. Molerov (Eds.). Modeling and Measuring Competencies in Higher Education - Validation and Methodological Innovations (KoKoHs) - Overview of the Research Projects (pp. 3943). Berlin \& Mainz: Humboldt University \& Johannes Gutenberg University.

Klibanoff, R. S., Levine, S. C., Huttenlocher, J., Vasilyeva, M., \& Hedges, L. V. (2006). Preschool children's mathematical knowledge: The effect of teacher "math talk.". Developmental Psychology, 42(1), 59-69. doi: 10.1037/0012-1649.42.1.59

Krajewski, K. (2018). MBK O. Test mathematischer Basiskompetenzen im Kindergartenalter. Göttingen: Hogrefe.

Krajewski, K., \& Schneider, W. (2009). Early development of quantity to number-word linkage as a precursor of mathematical school achievement and mathematical difficulties: Findings from a four-year longitudinal study. Learning and Instruction, 19(6), 513-526.

Linder, S. M., \& Simpson, A. (2017). Towards an understanding of early childhood mathematics education: A systematic review of the literature focusing on practicing and prospective teachers. Contemporary Issues in Early Childhood, 1-23. https://doi.org/10.1177/1463949117719553

Ma, X. (1999). A Meta-Analysis of the Relationship between Anxiety toward Mathematics and Achievement in Mathematics. Journal for Research in Mathematics Education, 30(5), 520-540.

Muthén, L. K., \& Muthén, B. O. (1998-2017). Mplus User's Guide. Eighth Edition. Los Angeles, CA: Muthén \& Muthén.

Nguyen, T., Watts, T. W., Duncan, G. J., Clements, D. H., Sarama, J. S., Wolfe, C., \& Spitler, M. E. (2016). Which preschool mathematics competencies are most predictive of fifth grade achievement? Early Childhood Research Quarterly, 26, 550-560.

O'Leary, K., Fitzpatrick, C. L., \& Hallett, D. (2017). Math anxiety is related to some, but not all, experiences with math. Frontiers in Psychology, 8(DEC), 1-14. https://doi.org/10.3389/fpsyg.2017.02067

Pekrun, R. (2006). The control-value theory of achievement emotions: Assumptions, corollaries, and implications for educational research and practice. Educational 
Psychology Review, 18(4), 315-341.

Piaget, J. \& Szeminska, A. (1975). Die Entwicklung des Zahlbegriffs beim Kinde. Stuttgart: KlettCotta.

Polya, G. 1977. Mathematical methods in science. Washington, DC: Mathematical Association of America.

Ramirez, G., Hooper, S. Y., Kersting, N. B., Ferguson, R., \& Yeager, D. (2018). Teacher Math Anxiety Relates to Adolescent Students' Math Achievement. AERA Open, 4(1), 1-13. https://doi.org/10.1177/2332858418756052

Ramirez, G., Shaw, S. T., \& Maloney, E. A. (2018). Math anxiety: Past research, promising interventions, and a new interpretation framework. Educational Psychologist, 1520, 120. https://doi.org/10.1080/00461520.2018.1447384

Schukajlow, S., Rakoczy, K., \& Pekrun, R. (2017). Emotions and motivation in mathematics education: theoretical considerations and empirical contributions. ZDM - Mathematics Education, 49(3), 307-322. https://doi.org/10.1007/s11858-017-0864-6

Stoet, G., Bailey, D. H., Moore, A. M., \& Geary, D. C. (2016). Countries with higher levels of gender equality show larger national sex differences in mathematics anxiety and relatively lower parental mathematics valuation for girls. PLOS ONE, 11(4), 1-24. https://doi.org/10.1371/journal.pone.0153857

Thiel, O. (2010). Teachers' attitudes towards mathematics in early childhood education. European Early Childhood Education Research Journal, 18(1), 105-115. doi: 10.1080/13502930903520090

Thiel, O., \& Jenßen, L. (2018). Affective-motivational aspects of early childhood teacher students' knowledge about mathematics. European Early Childhood Education Research Journal, 26(4), 512-534. https://doi.org/10.1080/1350293X.2018.1488398

Tirosh, D., Tsamir, P., Levenson, E., \& Tabach, M. (2011). From preschool teachers' professional development to children's knowledge: comparing sets. Journal of Mathematics Teacher Education, 14(2), 113-131. https://doi.org/10.1007/s10857-0119172-1

Trawick-Smith, J., Swaminathan, S., \& Liu, X. (2015). The relationship of teacher-child play interactions to mathematics learning in preschool. Early Child Development and Care, 186(5), 716-733. https://doi.org/10.1080/03004430.2015.1054818

Tsamir, P., Tirosh, D., Levenson, E., Tabach, M., \& Barkai, R. (2014a). Employing the CAMTE framework: Focusing on preschool teachers' knowledge and self-efficacy related to students' conceptions. In U. Kortenkamp, B. Brandt, C. Benz, G. Krummheuer, S. Ladel \& R. Vogel (Eds.), Early Mathematics Learning (pp. 291-306). New York: Springer Science+Business.

Ulferts, H., \& Anders, Y. (2016). Effects of ECEC on academic outcomes in literacy and mathematics: Meta-analysis of European longitudinal studies. 